\title{
Inhibition of the invasion and metastasis of mammary carcinoma cells by NBD peptide targeting S100A4 via the suppression of the Sp1/MMP-14 axis
}

\author{
KEIZO TAKENAGA ${ }^{1,6}$, TAKAHIRO OCHIYA ${ }^{2,3}$ and HIDEYA ENDO ${ }^{4,5}$ \\ ${ }^{1}$ Department of Life Science, Faculty of Medicine, Shimane University, Shimane 690-0823; \\ ${ }^{2}$ Division of Molecular and Cellular Medicine, National Cancer Center Research Institute, Tokyo 104-0045; \\ ${ }^{3}$ Department of Molecular and Cellular Medicine, Institute of Medical Science, Tokyo Medical University, Tokyo 160-0023; \\ ${ }^{4}$ Division of Cellular and Molecular Biology, Department of Cancer Biology, and ${ }^{5}$ Division of Molecular Pathology, \\ Institute of Medical Science, University of Tokyo, Tokyo 108-8639, Japan
}

Received June 4, 2020; Accepted December 12, 2020

DOI: $10.3892 /$ ijo.2021.5173

\begin{abstract}
A synthetic peptide that blocks the interaction between the metastasis-enhancing calcium-binding protein, S100A4, and its effector protein, methionine aminopeptidase 2 (MetAP2) (the NBD peptide), was previously demonstrated to inhibit the angiogenesis of endothelial cells, leading to the regression of human prostate cancer in a xenograft model. However, the effects of the NBD peptide on the malignant properties of cancer cells that express S100A4 remain to be elucidated. The present study demonstrates that the NBD peptide inhibits the invasiveness and metastasis of highly metastatic human mammary carcinoma cells. The introduction of the peptide into MDA-MB-231 variant cells resulted in the suppression of matrix degradation in a gelatin invadopodia assay and invasiveness in a Matrigel invasion assay. In line with these results, the peptide significantly downregulated the expression of matrix metalloproteinase (MMP)-14 (MT1-MMP). Mechanistic analysis of the downregulation of MMP-14 revealed the suppression of the expression of the transcription factor, specificity protein 1 (Sp1), but not that
\end{abstract}

Correspondence to: Dr Hideya Endo, Division of Molecular Pathology, Institute of Medical Science, University of Tokyo, 4-6-1 Shirokanedai, Minato-ku, Tokyo 108-8639, Japan

E-mail: endoh@ims.u-tokyo.ac.jp

Present address: ${ }^{6}$ Laboratory of Cancer Genetics, Chiba Cancer Center Research Institute, Chiba 260-8717, Japan

Abbreviations: DPBS, Dulbecco's phosphate-buffered saline; MMP, matrix metalloproteinase; MTA1, metastasis-associated protein 1; MetAP2, methionine aminopeptidase 2; NMIIA, non-muscle myosin II-A; Sp1, specificity protein 1; TIMP, tissue inhibitor of metalloproteinases

Key words: S100A4, peptide inhibitor, Sp1, MMP-14, invasion, metastasis, breast cancer of nuclear factor $(\mathrm{NF})-\kappa \mathrm{B}$, early growth response 1 (EGR1) or ELK3, all of which were reported to be involved in transcriptional regulation of the MMP-14 gene. At the same time, evidence suggested that the NBD peptide also suppressed Sp1 and MMP-14 expression levels in MDA-MB-468 cells. Importantly, the intravenous administration of the NBD peptide encapsulated in liposomes inhibited pulmonary metastasis from mammary gland tumors in mice with xenograft tumors. These results indicate that the NBD peptide can suppress malignant tumor growth through the suppression of the Sp1/MMP-14 axis. Taken together, these results reveal that the NBD peptide acts on not only endothelial cells, but also on tumor cells in an integrated manner, suggesting that the peptide may prove to be a promising cancer therapeutic peptide drug.

\section{Introduction}

The small EF-hand calcium-binding protein S100A4, a member of the S100 family, has been demonstrated to play important roles in invasion and metastasis in a number of different types of tumors $(1,2)$. Furthermore, its high expression has been shown to be associated with tumor aggressiveness and poor outcomes in patients with a variety of cancers (3). Although the precise molecular mechanisms underlying the S100A4-mediated enhancement of invasion and metastasis remain to be completely elucidated, a number of studies have revealed some of these mechanisms by focusing on the discovery of effector proteins with which S100A4 interacts in a $\mathrm{Ca}^{2+}$-dependent manner (3-6). To date, dozens of such effector proteins have been reported. For example, the authors previously identified methionine aminopeptidase 2 (MetAP2) as a binding partner of S100A4 that plays a key role in angiogenesis and acts as the target of the antiangiogenic natural product fumagillin and its analogs, such as TNP-470 $(4,5)$. The authors have also recently reported the association between S100A4 and the metastasis-associated protein MTA1 in the cytoplasm of murine endothelial cells, which resulted in the stabilization of the S100A4 protein by the inhibition of 
its ubiquitin-proteasome pathway-mediated degradation (6). As such, MTA1 siRNA inhibited tumor angiogenesis and tumor growth through the partial downregulation of S100A4 in a human pancreatic cancer xenograft model, suggesting that the MTA1-S100A4 axis is a target for cancer therapy. S100A4 also interacts with a variety of effector proteins, including the heavy chain of non-muscle myosin II-A (NMIIA), F-actin, tropomyosin, Liprin $\beta 1$, the Rho-binding domain of Rhotekin, the tumor suppressor p53 and Annexin A2, through which the complex probably regulates cell motility and apoptosis (6-14). Of note, previous studies have demonstrated S100A4 as a regulator of epithelial-mesenchymal transition and the properties of cancer stem cells (15-20).

Matrix metalloproteinases (MMPs) are zinc-dependent endopeptidases involved in extracellular matrix (ECM) degradation and remodeling $(21,22)$. The roles of MMPs in cancer cell invasion and metastasis have been extensively studied and have become better understood. Among MMPs, MMP-14 (also known as membrane-type 1 MMP, MT1-MMP) has been demonstrated to play essential roles in the breakdown of ECM, cell proliferation and cell motility $(23,24)$. MMP-14 binds to tissue inhibitor of metalloproteinases (TIMP)-2, which in turn binds pro-MMP-2 on the cell surface, where a second unbound MMP-14 protein cleaves the propeptide domain of pro-MMP-2, leading to its activation and ultimately the degradation of type IV collagen within the basement membrane (23-25). MMP-14 also activates MMP-13 and degrades various ECM components, including type I, II and III collagens, laminins and fibronectin $(23,24)$. Importantly, MMP-14 accumulates on the surface of invadopodia, which are actin-rich membrane projections formed by invasive tumor cells to degrade the basement membrane (26). In addition to its ECM-degradative function, recent research has revealed novel non-ECM-degradative functions of MMP-14. MMP-14 cleaves the N-terminal ligand-binding portion of the Eph receptor tyrosine kinase EphA2, leading to the loss of the suppressive effect of ligand-bound EphA2 on cell growth, ultimately enhancing the growth, migration and metastasis of cancer cells (27). The short cytoplasmic tail of MMP-14 binds factor-inhibiting HIF-1 (FIH-1), which activates the master regulator of the hypoxia response, hypoxia-inducible factor-1 (HIF-1) (28).

The authors have previously demonstrated that a synthetic peptide corresponding to the S100A4-binding domain of MetAP2 (NBD peptide), but not a control synthetic peptide (CBD peptide), efficiently blocked the S100A4-MetAP2 interaction (5). The NBD peptide is considered to occupy the binding pocket of $\mathrm{Ca}^{2+}$-bound S100A4 and hence block the binding of S100A4 to other effector proteins. The NBD peptide was found to enhance the assembly of NMIIA filaments, modulated the expression of angiogenesis-related genes, and inhibit cell growth and capillary formation in murine endothelial cells (5). Consequently, the NBD peptide significantly inhibited tumor angiogenesis and hence retarded tumor growth in a human prostate cancer xenograft model (4). As mentioned above, as metastatic cancer cells express a large amount of S100A4, the NBD peptide may also inhibit cancer cell invasion and metastasis. Given that the NBD peptide amino acid sequences in mouse and human MetAP2 are identical, the present study examined the unexplored possible effects of the NBD peptide in highly metastatic human mammary carcinoma cells.

\section{Materials and methods}

Cells. Highly metastatic human mammary carcinoma MDA-MB-231-Luc-D3H2LN (RRID: CVCL_D257) and MDA-MB-468 cells (ATCC ${ }^{\circledR}$ HTB-132 ${ }^{\mathrm{TM}}$ ) were obtained from Caliper Life Sciences (29) and the American Type Culture Collection (ATCC), respectively. In addition, 293 cells (JCRB9068) were supplied by Health Science Research Resources Bank. After confirming the absence of mycoplasma using the e-Myco Mycoplasma PCR Detection kit (Cosmo Bio Co., Ltd.), the cells were cultured in DMEM supplemented with $10 \%$ fetal bovine serum and $40 \mu \mathrm{g} / \mathrm{ml}$ gentamicin in a humidified atmosphere of $95 \%$ air $/ 5 \% \mathrm{CO}_{2}$ at $37^{\circ} \mathrm{C}$.

Peptide synthesis. The synthesis of the peptides (NBD corresponding to MetAP2 (170-229) and CBD corresponding to MetAP2 (192-229)) was carried out by the solid phase method with a Pioneer peptide synthesis system (Applied Biosystems; Thermo Fisher Scientific, Inc.), and the peptides were purified by reverse-phase high-performance liquid chromatography on a C18 column as previously described (5).

Peptide loading. The CBD and NBD peptides were introduced into the cells using atelocollagen mixed with BioPORTER protein delivery reagent (Genlantis, Inc.); throughout the experiment, the CBD peptide was used as a control peptide for the NBD peptide as previously described (5). For this purpose, the peptides $(12.5 \mu \mathrm{g})$ dissolved in $20 \mu \mathrm{l}$ of atelocollagen in Dulbecco's phosphate-buffered saline (DPBS) were added to a dry film of BioPORTER reagent (equivalent to $10 \mu \mathrm{l}$ of a BioPORTER solution) and mixed by pipetting. Following incubation for $5 \mathrm{~min}$ at room temperature, the solution was briefly vortexed and added to Opti-MEM (cat no. 31985070, Thermo Fisher Scientific, Inc.) to yield a final volume of $1 \mathrm{ml}$, which was then evenly distributed in a $60-\mathrm{mm}$ dish. Following incubation for $2 \mathrm{~h}$ in a $\mathrm{CO}_{2}$ incubator, MDA-MB-231-Luc-D3H2LN or MDA-MB-468 cells $\left(1.8 \times 10^{5}\right.$ cells $)$ were seeded in the dish and incubated at $37^{\circ} \mathrm{C}$ for $4 \mathrm{~h}$. After FBS was added to a final concentration of $10 \%$, both the MDA-MB-231-Luc-D3H2LN cells and MDA-MB-468 cells were further cultured for 18 and $40 \mathrm{~h}$, respectively.

Mithramycin A and fumagillin treatment. MDA-MB231-Luc-D3H2LN cells were treated with solvent alone (DMSO), mithramycin A (cat no. M6891, Sigma-Aldrich; Merck KGaA) or fumagillin (cat no. F6771, Calbiochem, Merck $\mathrm{KGaA}$ ) at the indicated concentrations and incubated at $37^{\circ} \mathrm{C}$ for 2 days.

RNA isolation and RT-qPCR. Total RNA was isolated using the RNAeasy Plus Mini kit (Qiagen $\mathrm{GmbH}$ ) according to the manufacture's protocol. The quantity and purity of the RNA were measured using a NanoDrop 2000c spectrophotometer (Thermo Fisher Scientific, Inc.). cDNA was synthesized using total RNA ( $1 \mu \mathrm{g})$ and the ReverTra Ace qPCR RT kit (Toyobo Life Science,) in a $10 \mu 1$ volume and then diluted 10 times with distilled water. PCR reactions were performed in $20 \mu \mathrm{l}$ volumes containing $1 \mu \mathrm{l}$ cDNA, $10 \mu \mathrm{l}$ PowerSYBR-Green PCR Master Mix (Applied Biosystems; Thermo Fisher Scientific, Inc.), $0.3 \mu \mathrm{l}$ of a mixture of forward and reverse primers (10 pmoles 
each) and 8.7 $\mu$ l RNase-free water. qPCR was carried out for triplicate samples using the 7500 Real Time PCR System (Applied Biosystems; Thermo Fisher Scientific, Inc.) in a PCR protocol consisting of an initial denaturation step at $95^{\circ} \mathrm{C}$ for $1 \mathrm{~min}$ and 40 cycles of denaturation $\left(95^{\circ} \mathrm{C}\right.$ for $\left.15 \mathrm{sec}\right)$ and extension $\left(60^{\circ} \mathrm{C}\right.$ for $\left.1 \mathrm{~min}\right)$. The $\mathrm{mRNA}$ expression level of each gene was normalized to that of glyceraldehyde-3-phosphate dehydrogenase $(G A P D H)$ using the $2^{-\Delta \Delta \mathrm{Cq}}$ method (30). The sequences of the specific primer sets are listed in Table SI.

Cell motility assay. A cell motility (wound healing) assay was performed with the MDA-MB-231-Luc-D3H2LN cells treated with CBD and NBD. After the cells had reached sub-confluence (approximately 75\%), the cells were pre-treated with $5 \mu \mathrm{g} /$ well of the CBD or NBD peptide/atelocollagen complex for $30 \mathrm{~min}$ in serum-free Opti-MEM, after which the cells were wounded by scraping the monolayer using a pipette tip and grown in DMEM with $2 \%$ FBS for $24 \mathrm{~h}$. The scratch closure was monitored and imaged using a Keyence BZ-X710 microscope (Keyence, Germany). The wound area was measured using NIH Image 1.47 software. Wound closure percentage was calculated as follows: Wound area $(\%)=$ AW/IW x100, where IW represents the initial wound area and AW the wound area at $24 \mathrm{~h}$.

Gelatin invadopodia assay. The ECM-degrading activity of the peptide-loaded cells was assessed using a QCM Gelatin Invadopodia Assay (Green) kit (EMD Millipore) according to the manufacturer's protocol. The MDA-MB-231-Luc-D3H2LN cells loaded with the NBD or CBD peptide or mock-treated cells were seeded onto fluorescein-labeled gelatin and cultured at $37^{\circ} \mathrm{C}$ for $24 \mathrm{~h}$. Following fixation with $4 \%$ formaldehyde in DPBS, the cells were stained with TRITC-phalloidin and DAPI at room temperature for $1 \mathrm{~h}$. Fluorescent images obtained using the TCS SP8 confocal laser scanning microscope (Leica Microsystems, Inc.) were analyzed using NIH ImageJ 1.52a software (31), and the degradation area (pixel value) was normalized to the number of cells per field.

Invasion assay. Cell invasion assay for the MDA-MB-231-Luc-D3H2LN cells was assessed using the CytoSelect 96-Well Cell Invasion Assay (Cell Biolabs, Inc.). The cells were pre-treated with $5 \mu \mathrm{g} /$ well of the CBD and NBD peptide/atelocollagen complex at $37^{\circ} \mathrm{C}$ for $30 \mathrm{~min}$ and then plated at $1 \times 10^{5}$ cells/well in 96-well plates. Cells that had invaded the Matrigel were stained with hematoxylin (cat no. H9627, Sigma-Aldrich; Merck KGaA) at room temperature for $5 \mathrm{~min}$, and the number of pores with stained cells was calculated. For the MDA-MB-468 cells, invasion assays were performed with Corning BioCoat Matrigel Invasion Chambers (Corning, Inc.), first by pre-treatment with either CBD or NBD peptide/atelocollagen complex at $12.5 \mu \mathrm{g} /$ well at $37^{\circ} \mathrm{C}$ for $18 \mathrm{~h}$, followed by re-plating at $5 \times 10^{4}$ cells/well in 96 -well plates. Invasive cells were stained with $0.5 \%$ crystal violet (cat no. V5265, Sigma-Aldrich; Merck KGaA) and quantified using a microscope (CX23, Olympus Corporation) as per the manufacturer's instructions.

Preparation of NBD peptide-encapsulated glycoliposomes. NBD peptide-encapsulated glycoliposomes with sialyl Lewis
$\mathrm{X}$ on their surface (NBD-GlycoLipos) were prepared using an improved cholate dialysis method and supplied by Katayama Chemical Industries Co., Ltd. (32). The lipid content of the obtained NBD-GlycoLipos was measured by determining the total cholesterol content using a Cholesterol E test Wako kit (FUJIFILM Wako Pure Chemical Corp.) after the GlycoLipos were destroyed in the presence of $3 \%$ sodium dodecyl sulfate. The total amount of fatty acids was then calculated from the molar ratio of each lipid. The protein content in the presence of $1 \%$ sodium dodecyl sulfate was determined using Pierce Micro BCA Protein Assay Reagent (Thermo Fisher Scientific, Inc.). Particle size and zeta potential at $25^{\circ} \mathrm{C}$ were measured using a Zetasizer Nano-ZSP (Malvern Panalytical, Ltd.). The NBD-GlycoLipo solution was diluted 50-fold with distilled water for measurements.

Spontaneous lung metastasis assay. Animal experiments were performed in compliance with the guidelines of the Institute for Laboratory Animal Research, National Cancer Center Research Institute (February to March, 2019). The protocol was approved by the National Cancer Center Research Institute (Approval no. NCC-T17-038). On day 0, the mammary glands of 6-week-old female CB-17 SCID mice (10 mice; average body weight, $23.4 \mathrm{~g}$; CLEA Japan) anesthetized by exposure to $3 \%$ isoflurane were injected with $1.5 \times 10^{6}$ MDA-MB-231-Luc-D3H2LN cells expressing luciferase and randomly divided into 3 groups. Mice were examined for their health by monitoring activity, body weight, food/water intake and coat/skin condition every 2 days during tumor progression following tumor transplantation. In addition, the size of the tumor xenografts was monitored so as not to exceed $10 \%$ of the animal's body weight at the experimental endpoint (the maximum tumor weight expressed as a percentage of the body weight in this study was $9.8 \%$ in a single subject in the empty-GlycoLipos group). On days 7 and 14, the mice were treated with only PBS only ( $n=2)$, empty glycoliposomes (empty-GlycoLipos; lipid concentration, $3.6 \mathrm{mg} / \mathrm{ml} ; \mathrm{n}=4$ ) or glycoliposomes containing the NBD peptide (NBD-GlycoLipos; lipid concentration, $3.6 \mathrm{mg} / \mathrm{ml}$; peptide concentration, $0.32 \mathrm{mg} / \mathrm{ml}$; $\mathrm{n}=4$ ) via the tail vein injection. On day 28 , the mice were subjected to imaging with an IVIS imaging system (Xenogen Corp.). For this, the mice were intraperitoneally injected with D-luciferin (150 mg/kg; Promega Corporation). After $10 \mathrm{~min}$, photons from Firefly luciferase were counted, and data were analyzed using LivingImage software (version 2.50; Xenogen Corp.) according to the manufacturer's instructions. During the process of live imaging, the mice were anesthetized with $4 \%$ isoflurane by inhalation and maintained with $1.5 \%$ isoflurane. As for the animal euthanasia procedure, a combination of anesthesia with isoflurane and cervical dislocation by a trained person in compliance with an IACUC-approved protocol was used. Animal death was confirmed by respiratory arrest and verifying no heartbeat by palpation. The primary tumor and the lung of each animal were resected at necropsy for tumor weight measurement and immunohistological analysis, respectively.

Immunohistochemical analysis of CD31. Primary tumors were surgically removed and fixed in a $10 \%$ phosphate-buffered formalin solution. The tissues were embedded in paraffin and 
cut into 5- $\mu \mathrm{m}$-thick sections. Following heat-induced antigen retrieval by REAL Target Retrieval Solution (DAKO) and the subsequent blocking of non-specific sites with $0.1 \%$ normal goat serum $/ 1 \% \mathrm{BSA}$ at $4^{\circ} \mathrm{C}$ overnight, the tissue sections were stained with rabbit monoclonal anti-CD31 (PECAM-1) (D8V9E) XP antibody (diluted 1:100; cat no. \#77699, Cell Signaling Technology, Inc.) at room temperature for $1 \mathrm{~h}$ and visualized by staining with Alexa Fluor 594-conjugated goat anti-rabbit IgG (diluted 1:300; cat no. A32740, Thermo Fisher Scientific, Inc.) at room temperature for $1 \mathrm{~h}$ and counterstaining with DAPI at room temperature for $30 \mathrm{~min}$. Image acquisition was performed on a Leica TCS SC8 confocal laser scanning microscope (Leica Microsystems, Inc.), and tumor vessel densities were calculated using pixel values of CD31-positive regions in ImageJ software (National Institutes of Health).

Evaluation of pulmonary metastases. The level of metastasis at the thoracic cavity was evaluated based on immunohistochemistry. Lung tissues dissected from the mice were fixed in a $4 \%$ paraformaldehyde phosphate buffer solution (FUJIFILM Wako Pure Chemical Corporation) and embedded in paraffin. Each section was deparaffinized and rehydrated, and antigens were then activated by heating at $95^{\circ} \mathrm{C}$ for $45 \mathrm{~min}$ in Immunosaver solution (Nissin EM). Human tumor cells were detected by incubation with anti-human vimentin antibody (diluted 1:100; cat no. VP-RM17, rabbit anti-human vimentin monoclonal antibody, Vector Laboratories, Inc.) at $4^{\circ} \mathrm{C}$ overnight, followed by incubation with ImmPRESS anti-rabbit IgG (diluted 1:200, cat. no. MP-7401, Vector Laboratories) at room temperature for $1 \mathrm{~h}$. DAB staining was carried out using a Metal-Enhanced DAB Substrate kit (Thermo Fisher Scientific, Inc.), followed by hematoxylin staining at room temperature for $10 \mathrm{~min}$ and dehydration. The slides were subjected to microscopic observation using a BZ-X710 microscope (Keyence Corporation) with a $10 \mathrm{X}$ objective lens. The metastatic foci in the lungs of each treatment group were quantified by counting using a Digit Hand Tally Counter (AF-counter-2_hook+base, AFUNTA Technology Development Co., Ltd.), and the numbers of metastatic foci per area $\left(\mathrm{cm}^{2}\right)$ were calculated.

Western blot analysis. MDA-MB-231-Luc-D3H2LN or MDA-MB-468 cells cultured in 6-well plates were mock-treated or treated with $5 \mu \mathrm{g} /$ well of the NBD or the CBD peptide/atelocollagen complex for $18 \mathrm{~h}$ and then lysed in RIPA buffer $(150 \mathrm{mM}$ $\mathrm{NaCl}, 25$ mM Tris-HCl, pH 7.6, 1\% NP-40, 1\% sodium deoxycholate and $0.1 \%$ SDS) containing protease inhibitor cocktail (Roche Applied Science). The lysates were centrifuged at 10,000 x g for 10 min at $4^{\circ} \mathrm{C}$, and the supernatant was used for western blot analysis. The protein concentration was determined using the Bradford method. Proteins ( $40 \mu \mathrm{g}$ protein/lane) were denatured by boiling in SDS sample buffer and separated by $10 \%$ SDS-PAGE under reducing conditions and transferred to an Immobilon-P transfer membrane (EMD Millipore). The membrane was blocked with BLOCK ACE (DS Pharma Biomedical Co., Ltd.) in Tris-buffered saline and $0.1 \%$ Tween-20 (TBS-T) for $1 \mathrm{~h}$ at room temperature, incubated with primary antibodies (diluted 1:1,000) against MMP-14/MT1-MMP (cat. no. MAB9181-SP, mouse anti-human MMP-14/MT1-MMP monoclonal antibody; R\&D Systems, Inc.), Sp1 (cat. no. HPA001853, rabbit anti-human Sp1 polyclonal antibody; Sigma-Aldrich; Merck KGaA), IкB- $\alpha$ (cat.no.4812, rabbit anti-human IкB- $\alpha$ monoclonal antibody; Cell Signaling Technology, Inc.), phospho-IкB- $\alpha$ [Ser32; cat. no. 2859, rabbit anti-phospho-IкB- $\alpha$ (Ser32) monoclonal antibody; Cell Signaling Technology, Inc.], S100A4 (cat. no. ab27957, rabbit anti-human S100A4 polyclonal antibody; Abcam) and $\beta$-actin (cat no. sc-47778, mouse anti- $\beta$-actin monoclonal antibody, Santa Cruz Biotechnology, Inc.) at room temperature for $1 \mathrm{~h}$ or at $4^{\circ} \mathrm{C}$ overnight. The membrane was washed extensively with TBS-T, and then incubated with HRP-conjugated anti-rabbit IgG (diluted 1:3,000; cat no. \#7074S, Cell Signaling Technology, Inc.) or HRP-conjugated anti-mouse IgG (diluted 1:3,000; cat no. \#7076S, Cell Signaling Technology, Inc.) for $1 \mathrm{~h}$ at room temperature. Immunodetection was carried out using ECL Plus Western Blotting Detection Reagent (Amersham Biosciences; Thermo Fisher Scientific, Inc.). The density of the blots was analyzed using NIH ImageJ 1.52a software.

Immunofluorescence staining. The MDA-MB-231-LucD3H2LN cells cultured in 6-well plates were mock-treated or treated with the NBD or CBD peptide/atelocollagen complex for $18 \mathrm{~h}$ and fixed for 10 min with $4 \%$ formaldehyde in DPBS. Permeabilization of the cells was performed by incubating the fixed cells with $0.5 \%$ Triton X-100 in DPBS for 4 min. To block non-specific binding, the cells were then incubated with $3 \%$ BSA in DPBS containing $0.1 \%$ glycine for $1 \mathrm{~h}$. After washing with DPBS, the cells were incubated at room temperature for $1 \mathrm{~h}$ with primary antibodies (diluted 1:200) against MMP-14/MT1-MMP (cat. no. MAB9181-SP; R\&D Systems, Inc.), Sp1 (cat. no. HPA001853; Sigma-Aldrich; Merck KGaA), nuclear factor (NF)-кB p65 (cat. no. sc-372, rabbit anti-human NF- $\kappa$ B p65 polyclonal antibody; Santa Cruz Biotechnology, Inc.), early growth response 1 (EGR1; cat. no. 4153, rabbit anti-human EGR1 monoclonal antibody; Cell Signaling Technology, Inc.) and ELK3 (cat. no. GTX114966, rabbit anti-human ELK3 polyclonal antibody; GeneTex, Inc.). After rinsing with DPBS, the cells were stained with an appropriate Alexa Fluor 488- or Alexa Fluor 594-conjugated secondary antibody (diluted 1:300; Thermo Fisher Scientific, Inc.) at room temperature for $1 \mathrm{~h}$. Nuclei were counterstained with $1 \mu \mathrm{g} / \mathrm{ml}$ DAPI at room temperature for $15 \mathrm{~min}$. The cells were observed under a confocal laser scanning microscope (FluoView FV1000, Olympus Corporation).

Statistical analysis. Data are expressed as the means \pm standard deviation. No statistical method was used to predetermine the sample size. The researchers were not blinded to allocation during experiments and outcome assessment. Statistical analyses were conducted using one-way ANOVA and Tukey's test. A P-value of $\leq 0.05$ was considered to indicate a statistically significant difference.

\section{Results}

Inhibition of cell motility, ECM-degrading activity and invasion by the NBD peptide in MDA-MB-231 variants. The expression of S100A4 was first examined in MDA-MB-231-Luc-D3H2LN cells by western blot analysis with 293 cells (S100A4-negative per the Human Protein Atlas) as a control, and found that there was a substantial amount of S100A4 expressed in the cells; the NBD peptide and CBD 


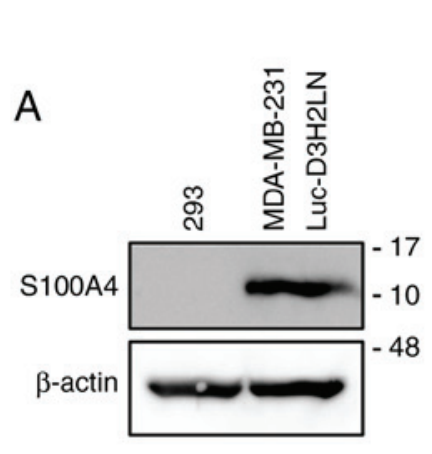

B
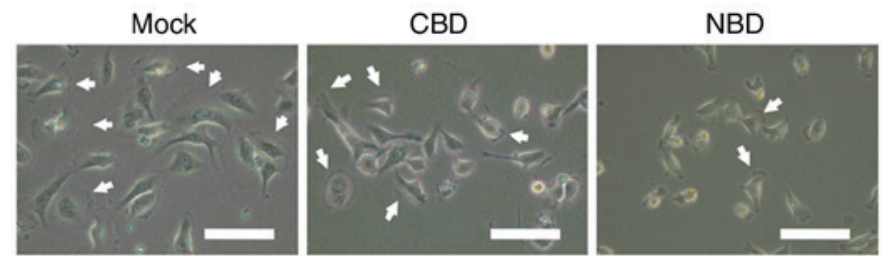

C
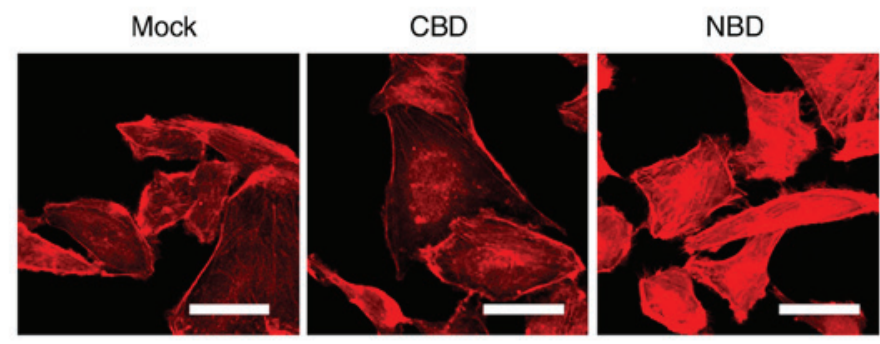

D

CBD
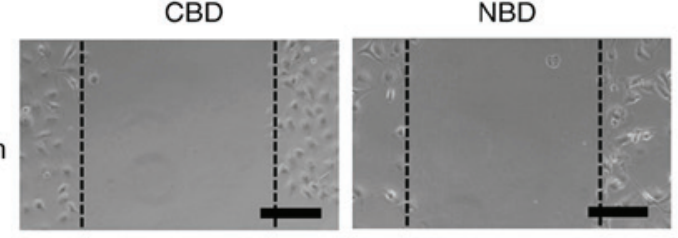

$24 \mathrm{~h}$
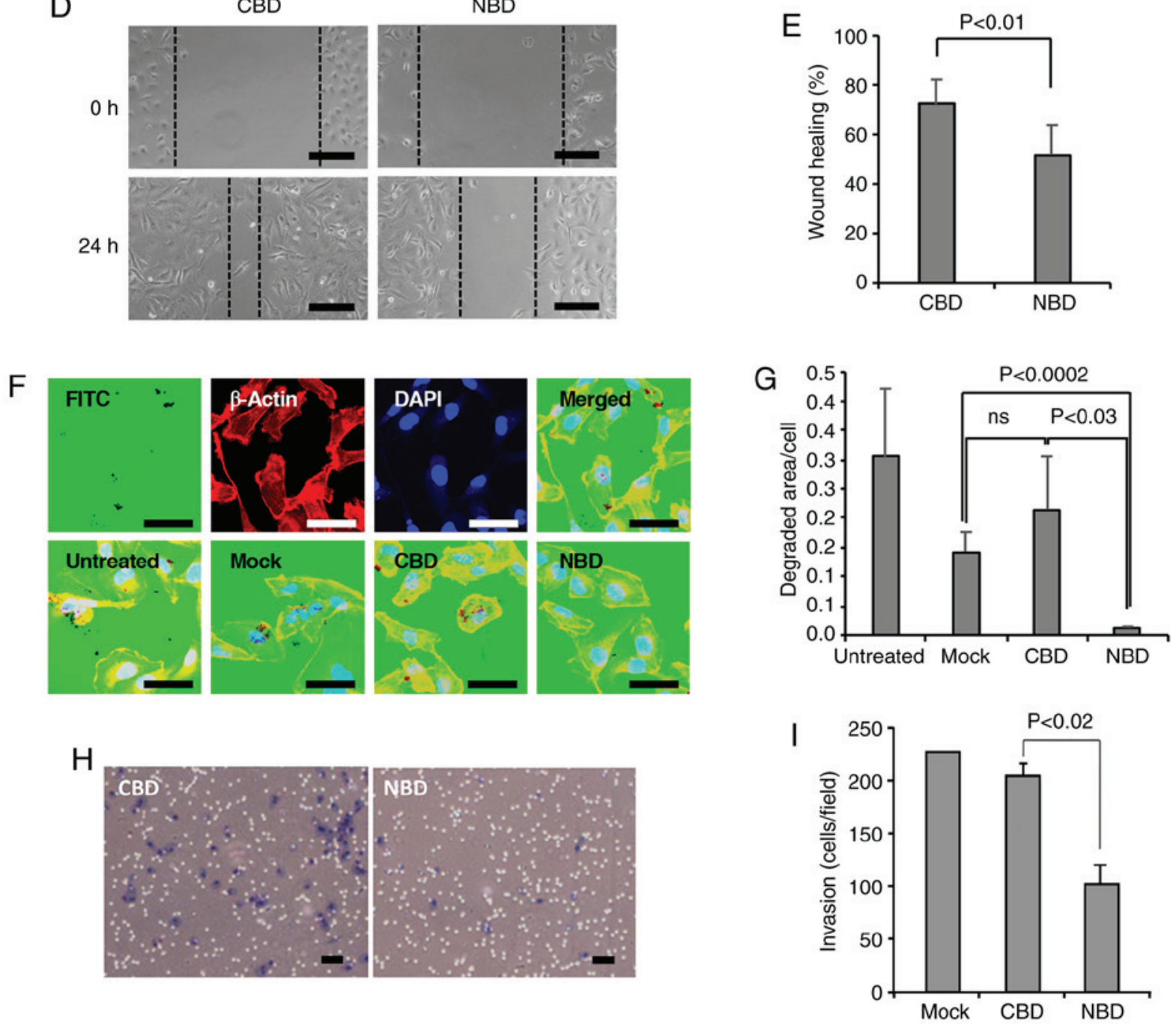

Figure 1. Inhibition of cell motility, ECM-degrading activity and invasiveness of MDA-MB-231-Luc-D3H2LN cells by the NBD peptide. (A) Western blot analyses of the expression of S100A4. Full size images of the western blots are shown in Fig. S6. (B) Morphology of mock-treated cells (only the peptide loading reagent) or cells treated with the CBD or NBD peptide. Bars: $100 \mu \mathrm{m}$. Arrows indicate examples of lamellipodia. (C) Actin stress fiber formation. Visualization of F-actin in mock-treated, CBD peptide-treated and NBD peptide-treated cells by TRITC-phalloidin staining. Bars: $20 \mu \mathrm{m}$. (D) Cell motility. Images showing the cell motility of the CBD peptide- and NBD peptide-treated cells examined by a wound healing assay. The images were photographed at $0 \mathrm{~h}$ and after $24 \mathrm{~h}$. Scale bars, $100 \mu \mathrm{m}$. (E) Quantification of cell motility. The motility of CBD peptide-treated and NBD peptide-treated cells was evaluated using the images obtained by a wound healing assay ( $n=6$ for each). (F) Gelatin invadopodia assay. Upper panels represent images showing the degradation of FITC-labeled gelatin (leftmost), TRITC-phalloidin staining (second from left), and DAPI staining (third from left) and a merged image (rightmost). Lower panels represent merged images of FITC-gelatin staining, TRITC-phalloidin staining and DAPI staining of untreated (leftmost), mock-treated (second from left), CBD peptide-treated (third from left) and NBD peptide-treated (rightmost) cells. Scale bars, $20 \mu \mathrm{m}$. (G) Quantification of the degraded area/cell in the invadopodia assay. The degradation area (pixel value) was normalized to the number of cells per field (Untreated, $n=10$ fields; Mock, $n=10$ fields; CBD, $n=12$ fields; NBD, n=13 fields); ns, not significant. (H) Matrigel invasion assay. Images showing the invasion of the CBD peptide- and NBD peptide-treated cells. Scale bars, $100 \mu \mathrm{m}$. (I) Quantification of the number of invaded cells ( $\mathrm{n}=4$ membranes for each). 

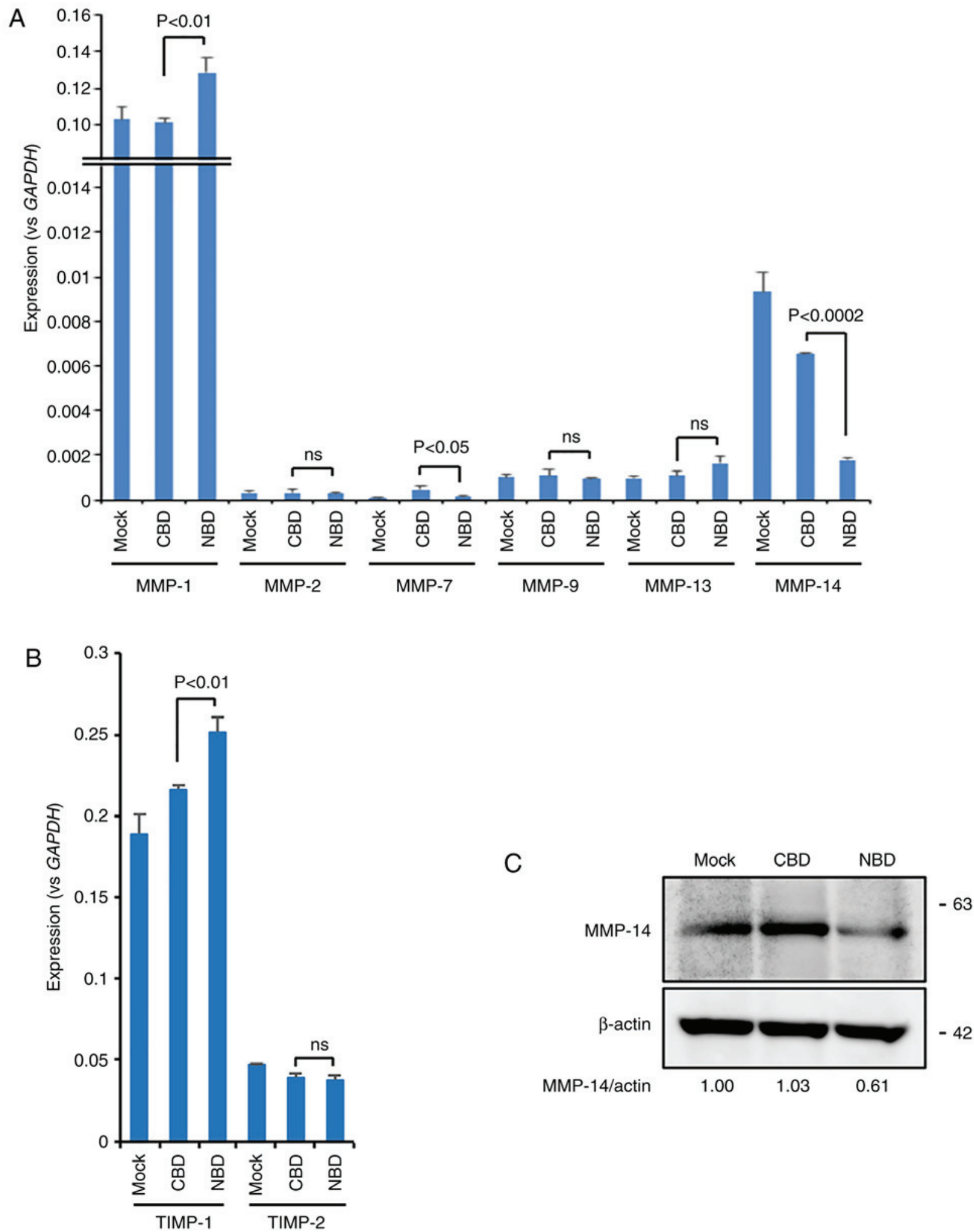

Figure 2. Suppression of MMP-14 expression by the NBD peptide in MDA-MB-231-Luc-D3H2LN cells. (A) RT-qPCR analyses of the expression of MMPs in mock-treated, CBD peptide-treated and NBD peptide-treated cells ( $\mathrm{n}=3$ ); ns, not significant. (B) RT-qPCR analyses of the expression of TIMP-1 and TIMP-2 in mock-treated, CBD peptide-treated and NBD peptide-treated cells $(n=3)$; ns, not significant. (C) Western blot analysis of the expression of MMP-14 in mock-treated, CBD peptide-treated and NBD peptide-treated cells. $\beta$-actin was used as a loading control. Full size images of the western blots are shown in Fig. S6.

peptide as a control were then introduced into these cells (Fig. 1A). Of note, the NBD peptide seemed to decrease lamellipodia formation compared to that following CBD peptide loading (Fig. 1B). In support of this finding, staining of the cells with TRITC-phalloidin revealed that F-actin was mainly localized at the periphery of the cells, probably at the lamellipodia, in the mock-treated and CBD peptide-loaded cells, while dense stress fibers were evident in the cell bodies of the 

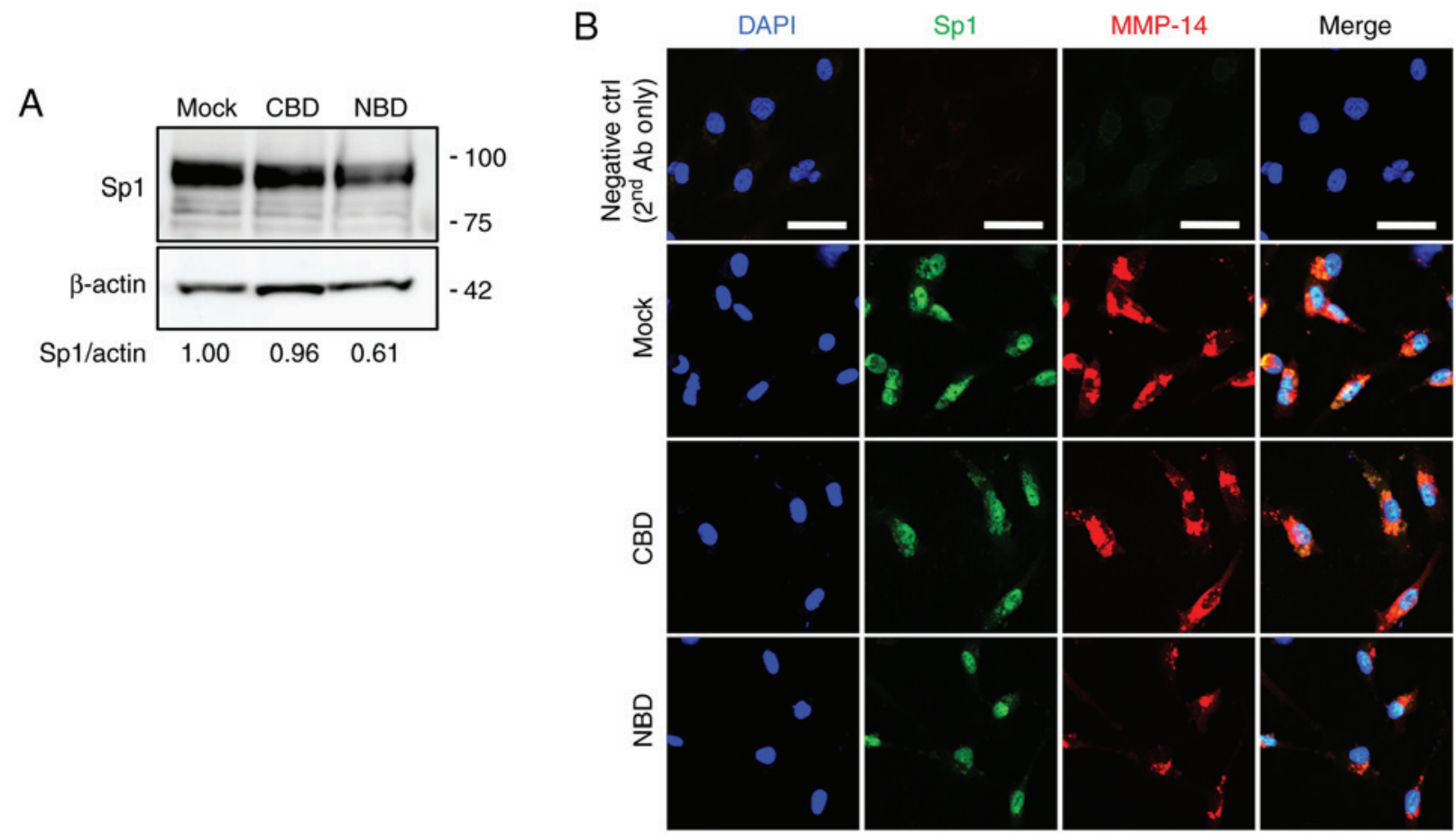

Figure 3. Suppression of Sp1 expression by the NBD peptide in MDA-MB-231-Luc-D3H2LN cells. (A) Western blot analysis of the expression of Sp1 in mock-treated, CBD peptide-treated and NBD peptide-treated cells. $\beta$-actin was used as a loading control. Full size images of the western blots are shown in Fig. S6. (B) Double immunofluorescence staining for Sp1 and MMP-14 in mock-treated, CBD peptide-treated and NBD peptide-treated cells. Nuclei were counterstained with DAPI. Scale bars, $50 \mu \mathrm{m}$.

NBD peptide-loaded cells (Fig. 1C). The authors previously reported similar results in NBD peptide-loaded endothelial cells, along with enhanced NMIIA phosphorylation (5). As lamellipodia extension is important for cell motility and invasion (33), the motile activity and ECM-degrading activity of the peptide-loaded cells was then measured using a wound healing assay and a gelatin invadopodia assay, respectively. The results revealed that the NBD peptide markedly suppressed cell motility (Fig. 1D and E), and the ECM-degrading activity of the NBD peptide-loaded cells was much weaker than that of the CBD peptide-loaded cells and mock-treated cells (Fig. 1F and G). In line with these results, the Matrigel invasion assay demonstrated a reduction in the invasiveness of the NBD peptide-loaded cells compared with the CBD peptide-loaded cells (Fig. $1 \mathrm{H}$ and I).

Decrease in the expression of MMP-14 in the NBD peptide-loaded cells. To obtain insights into the mechanisms underlying the reduction in cell motility and invasiveness in NBD peptide-loaded MDA-MB-231-Luc-D3H2LN cells, the expression levels of MMPs and their inhibitors, TIMPs, were examined. Notably, the results of RT-qPCR revealed that MMP-14 expression was significantly downregulated, while MMP-7 expression was slightly, yet significantly downregulated in the NBD peptide-loaded cells compared to the CBD peptide-loaded cells (Fig. 2A). MMP-1 and TIMP-1 expression was significantly increased. The expression levels of other MMPs (MMP-2, MMP-9 and MMP-13) and TIMP-2 were only slightly altered by the NBD peptide (Fig. 2A and B). The reduction in MMP-14 expression was also confirmed at the protein level (Fig. 2C).
Decreased Spl expression is involved in the downregulation of MMP-14 expression in the NBD peptide-loaded cells. The transcription of the MMP-14 gene is regulated by several transcription factors, including Sp1, NF- $\kappa \mathrm{B}$, EGR1 and ELK3 (34-38). The present study then examined the expression of these transcription factors and it was found that Sp1 was downregulated in the NBD peptide-loaded MDA-MB-231-Luc-D3H2LN cells (Fig. 3A). This was corroborated by double immunostaining experiments in which the expression levels of Sp1 and MMP-14 were decreased in the NBD peptide-loaded cells (Fig. 3B). No marked changes were detected in either the expression or intracellular localization of NF- $\kappa \mathrm{B}$ or the phosphorylation of I $\kappa \mathrm{B}-\alpha$ (Fig. S1). Likewise, no marked alterations were observed in the expression level or localization of EGR1 or ELK3, as assessed by immunofluorescence staining (Fig. S2), although western blot analysis might allow for the more detailed characterization of the two proteins. The involvement of Sp1 in the regulation of MMP-14 in MDA-MB-231-Luc-D3H2LN cells was also demonstrated by the inhibition of MMP-14 expression in the cells treated with the Sp1 inhibitor, mithramycin A (Fig. S3).

Decrease in MMP-14 and Spl expression levels in the NBD peptide-loaded MDA-MB-468 cells. To address whether the NBD peptide also suppresses MMP-14 and Sp1 expression levels in other mammary carcinoma cell lines, both NBD peptide and CBD (control) peptides were loaded into MDA-MB-468 cells that were confirmed to express S100A4 (Fig. 4A), and the suppression of lamellipodia formation (Fig. 4B) was observed in the samples that received NBD; additionally, it was also noted that the NBD peptide decreased the 
A

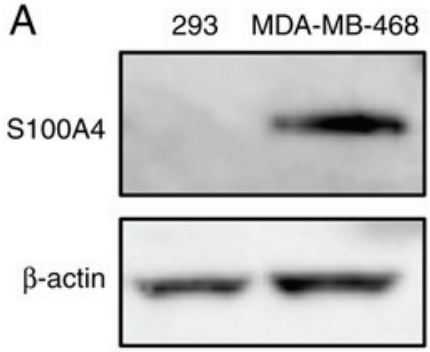

C

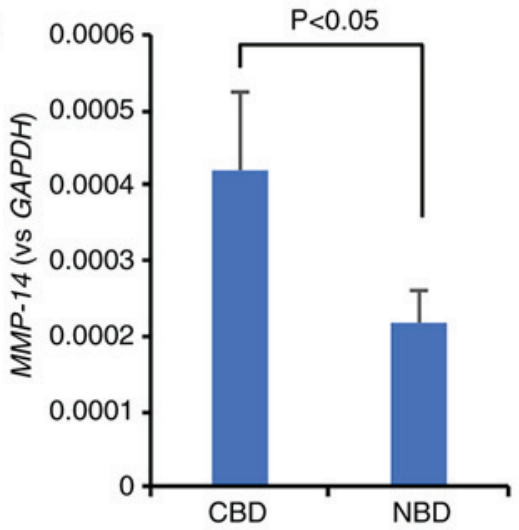

E

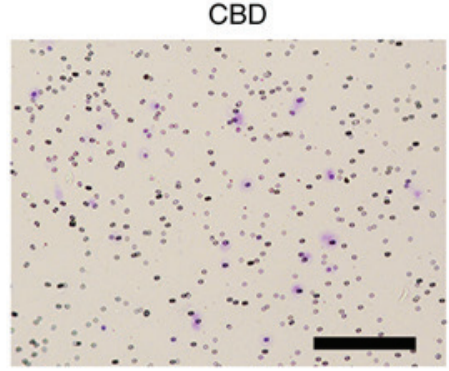

B

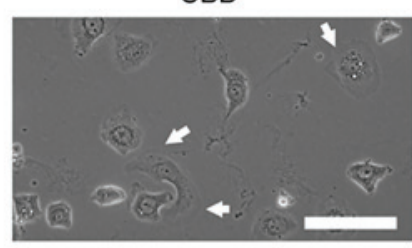

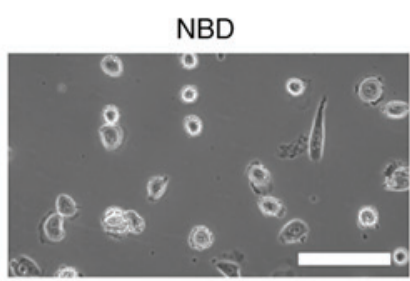

D

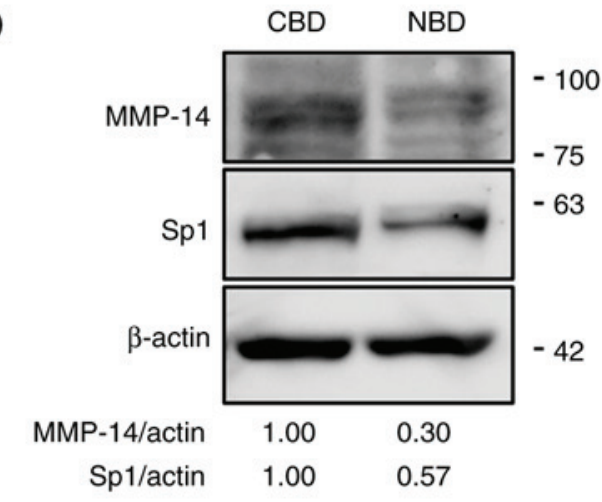

$\mathrm{F}$
$\mathrm{P}<0.01$

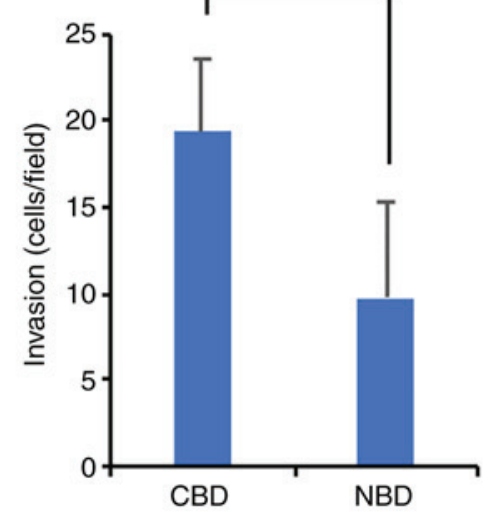

Figure 4. Suppression of lamellipodia formation and the expression of MMP-14 and Spl by the NBD peptide in MDA-MB-468 cells. (A) Western blots of S100A4, with full size images shown in Fig. S6. (B) Cell morphology as a response to CBD or NBD treatment. Scale bars, $100 \mu$ m. Arrows indicate examples of lamellipodia. (C) RT-qPCR analyses of differences in MMP-14 expression upon CBD and NBD peptide treatment (n=3 each). (D) Western blots of MMP-14 and Sp1 in CBD and NBD peptide-treated cells (loading control: $\beta$-actin), with full size images presented in Fig. S6. (E) Matrigel invasion assay. Images showing invasion of the CBD peptide- and NBD peptide-treated cells. Scale bars, $200 \mu \mathrm{m}$. (F) Quantitation of the number of invaded cells ( $\mathrm{n}=10$ fields).

expression of MMP-14 and Sp1 compared to the CBD control (Fig. 4C and D). The Matrigel invasion assay also demonstrated a significant reduction in the invasiveness of the NBD peptide-loaded cells compared to the CBD peptide-loaded control cells (Fig. 4E and F). These observations suggest that the NBD peptide affects the Sp1/MMP-14 axis in different mammary carcinoma cell lines.

MetAP2 enzyme activity is dispensable for the reduction in $M M P-14$. The NBD peptide may dissociate the S100A4-MetAP2 complex, releasing MetAP2 in the cytoplasm. To address whether the enzyme activity of MetAP2 is necessary for the reduction in MMP-14, we treated MDA-MB-231-Luc-Luc-D3H2LN cells with fumagillin. The results revealed that MMP-14 expression was not affected by this treatment (Fig. S4), indicating that the enzyme activity is dispensable.
Inhibition of lung metastasis of MDA-MB-231-Luc-D3H2LN cells by NDB peptide-loaded particles. To examine whether the NBD peptide suppresses the spontaneous metastasis of MDA-MB-231-Luc-D3H2LN cells, the cells were implanted into the mammary glands of SCID mice on day 0 . The mice then received intravenous injections of PBS, Empty-GlycoLipos or NBD-GlycoLipos on days 7 and 14 following implantation (Fig. 5A). The body weight of mice was comparable among the treatment groups (Fig. 5B). Compared to the Empty-GlycoLipos group, NBD-GlycoLipos was not found to inhibit primary tumor growth, either in vivo imaging on day 28 (Fig. 5C) or by tumor weight assessment on day 35 (Fig. 5D). The NBD peptide also did not suppress angiogenesis, which was assessed by CD31 immunohistochemical staining (Fig. S5). The present study was unable to observe evidence of metastases in the lungs in whole-body bioluminescent images due to the oversaturation of strong 


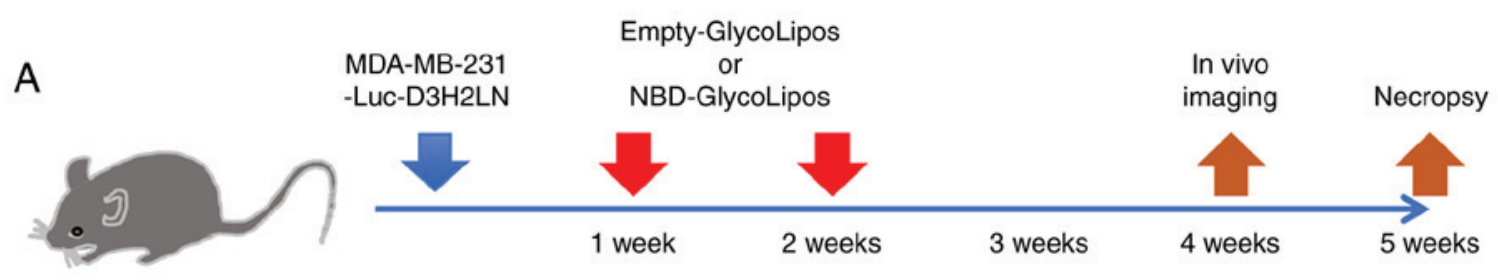

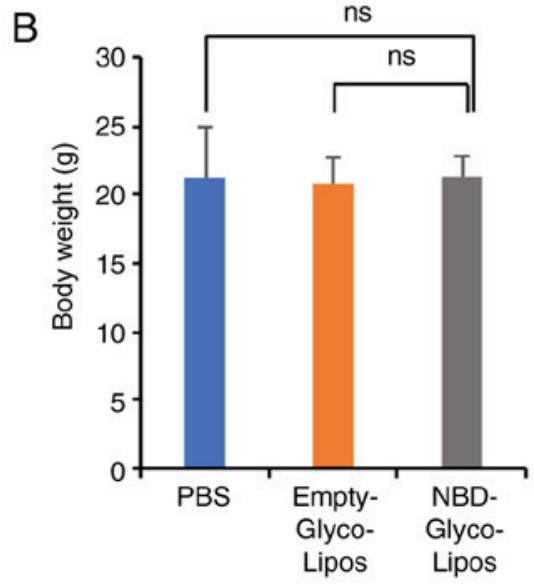

$\mathrm{E}$
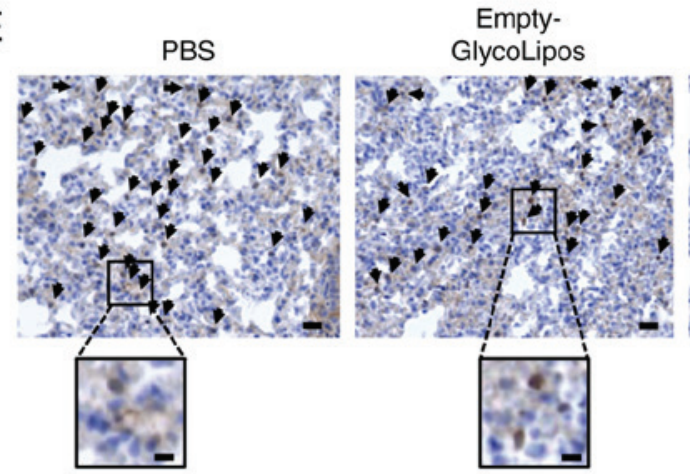

C
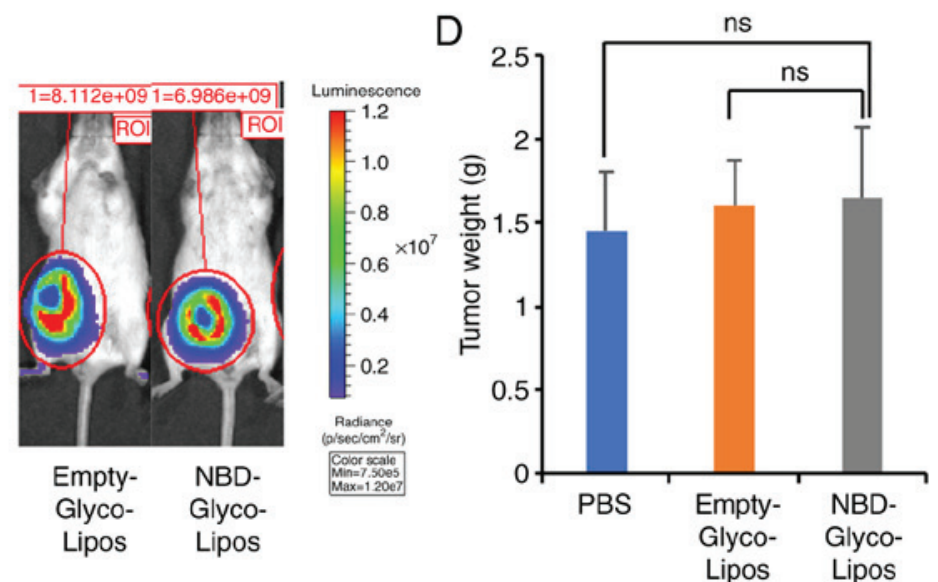

F

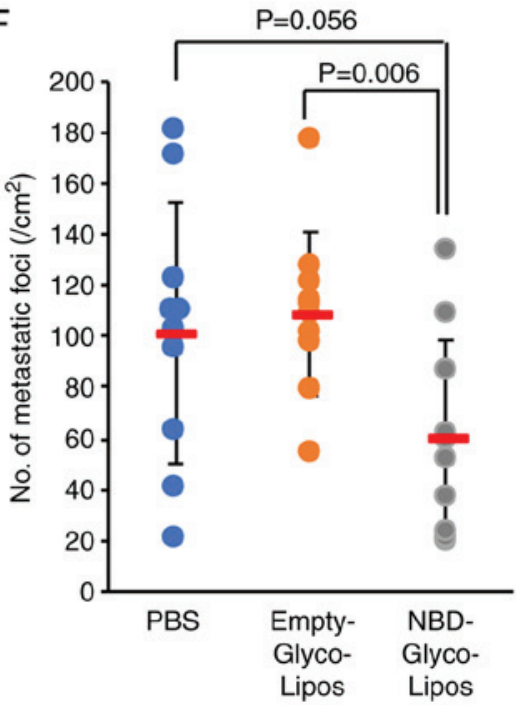

Figure 5. Inhibition of spontaneous lung metastasis by NDB peptide-loaded particles. (A) Schedule of the in vivo experiments. Empty liposomes (Empty-GlycoLipos) $(\mathrm{n}=4)$, NBD peptide-loaded liposomes (NBD-GlycoLipos) $(\mathrm{n}=4)$ and control saline (PBS) $(\mathrm{n}=2)$ were intravenously administered on days 7 and 14 following tumor cell implantation. On day 28, subcutaneous tumor growth was examined by in vivo imaging. On day 35 , the lungs were removed at necropsy and subjected to immunohistological examination for micro- and macrometastases. (B) Body weight of mice on day 35. (C) Bioluminescent images of primary tumors. (D) Primary tumor weight; ns: Not significant. (E) Metastases in the lungs detected by immunostaining with anti-human vimentin antibody. Arrows indicate examples of vimentin-positive cells. Scale bar, $20 \mu \mathrm{m}$. (F) Lung metastasis. The numbers of metastatic foci per area $\left(\mathrm{cm}^{2}\right)$ were calculated after staining of vimentin ( $\mathrm{n}=10$ areas for each treatment group)

luminescence intensity emitted from parts of the primary tumor. Subsequently, to observe disseminated tumor cells in the lungs, immunohistochemistry was performed with sections of the lungs using anti-human vimentin antibody (Fig. 5E). As a result, a significant reduction in the number of metastatic foci was observed in the NBD peptide-loaded particle-treated mice compared with the control particle-treated mice (Fig. 5F).

\section{Discussion}

The present study demonstrated that the NBD peptide significantly inhibited the invasiveness of highly metastatic mammary carcinoma MDA-MB-231-Luc-D3H2LN cells through the suppression of cell motility and invasiveness. Simultaneously, the expression of MMP-14, which plays a central role in cancer cell invasion and metastasis, was suppressed by the peptide. Most importantly, the intravenous injection of liposomes containing the NBD peptide appeared to significantly inhibit the spontaneous metastasis of these cells. Although the authors previously reported that the intratumoral injection of the NBD peptide complexed with atelocollagen could potentially inhibit tumor angiogenesis (5), the present study was unable to find any measurable difference in vessel density in the primary tumors of mice injected with the NBD peptide containing-liposomes 
compared to the control group, most likely due to the differences in the formulation, the injection route as well as the local concentration of the peptide. It was therefore hypothesized that a likely reason for the suppressive effect by the liposomes was due to the inhibition of the extravasation of the tumor cells or tumor angiogenesis in the lungs, rather than the inhibition of tumor angiogenesis in the primary tumors. This hypothesis was corroborated by the fact that no significant difference was observed in the primary tumor growth rate between the control and the NBD peptide-treated groups. Taken together, these results suggest that the NBD peptide can suppress tumor cell invasion and metastasis when administered in vivo.

In the present study, the CBD peptide was used as a control peptide as previously described (5), and a mild suppression of MMP-14 expression was noted in the CBD-peptide-loaded cells compared to the mock-treated cells (Fig. 2A); therefore, the presence of non-specific effects from CBD peptide introduction should not be discounted. Nevertheless, it was noted that the suppressive effect of the NBD peptide was reproducibly more potent compared to that of CBD in both the MDA-MB-231 and MDA-MB-468 cells, a result that highlighted the specific action of the NBD peptide.

S100A4 interacts with the C-terminus of NMIIA, and this interaction controls myosin filament assembly through the regulation of NMIIA phosphorylation at S1943 $(8,39)$. In a previous study by the authors, the NBD peptide enhanced NMIIA phosphorylation at S1943 in endothelial cells and stimulated myosin filament assembly and actin stress fiber formation (5). Therefore, NMIIA filaments were also considered to be assembled in MDA-MB-231-Luc-D3H2LN cells treated with the NBD peptide. On the other hand, actin assembly with non-muscle tropomyosin assembly has been reported to recruit NMIIA (40). This may indicate the formation of thicker and more stable actin stress fibers, as observed in stationary cells compared to highly motile cells (41). Indeed, prominent actin stress fiber formation was observed in the cell bodies of the NBD peptide-loaded cells. This change may also suppress the formation of invadopodia, where the branched F-actin network, cortactin and MMP-14 are concentrated, resulting in a reduction in focal degradation of the ECM (26). Certainly, the gelatin invadopodia assay showed a marked reduction in ECM degradation.

The mechanism of the transcriptional regulation of the MMP-14 gene has yet not been fully resolved; however, a number of transcription factors involved in regulating MMP-14, such as NF- $\mathrm{KB}, \mathrm{Sp} 1$, EGR1 and ELK3, have been reported (34-38). Among these, Sp1 was specifically downregulated in the NBD peptide-loaded cells. Although the involvement of $\mathrm{Sp} 1$ in the regulation of MMP-14 in MDA-MB-231-Luc-D3H2LN cells was confirmed by the mithramycin A1 experiment, Sp1 has also been reported to regulate transcription of the $M M P-2$, MMP-9, TIMP-1 and TIMP-2 genes (42-44). Although the reasons for the fact that MMP-14 was mainly downregulated in the NBD peptide-loaded cells cannot be explained at present, the transcription of the $M M P-14$ gene may be more dependent on $\mathrm{Sp} 1$ than that of other MMP and TIMP genes. This issue warrants further investigation in the future.

It should be noted that the NBD peptide also suppressed lamellipodia formation and the expression levels of MMP-14 and Sp1 in the MDA-MB-468 cells, suggesting the likelihood of the Sp1-MMP-14 axis being inhibited in S100A4-expressing cancer cells; this in turn led to the suppression of the invasion and metastasis of mammary carcinoma cells. Future studies into the involvement of Sp1-MMP-14 axis in invasion and metastasis by Sp1 and MMP-14 knockdown would be able to further elucidate the underlying mechanisms.

The NBD peptide may dissociate the S100A4-MetAP2 complex, releasing MetAP2 in the cytoplasm. The authors previously reported that the binding of S100A4 to MetAP2 did not affect methionine aminopeptidase activity, but altered the intracellular localization of MetAP2 (4). Therefore, it is possible that the enzyme activity of MetAP2 in the right place is necessary for the reduction in MMP-14. To address this issue, in the present study, cells were treated with fumagillin. However, MMP-14 expression was not affected by this treatment These results suggest that MetAP2 activity is dispensable and that NBD peptide-mediated blockade of the binding of other effector proteins with a lower affinity to the binding pocket in S100A4 is important for the decrease in Sp1 and MMP-14 expression. In this context, it is interesting to note that S100A4 binds MTA1 in the cytoplasm and that MTA1 induces expression of the tumor suppressor alternative reading frame (ARF) through corecruitment of c-Jun onto the $A R F$ promoter $(5,45)$. ARF interacts with $\mathrm{Sp} 1$ and promotes its proteasomal degradation by enhancing its interaction with the proteasome subunit regulatory particle ATPase 6 (45). Subsequently, if the NBD peptide blocks the interaction between S100A4 and MTA1, free MTA1 may translocate into the nucleus and induce ARF, in turn promoting Sp1 degradation. An examination of this possibility may be worthwhile in the future.

Therapeutic peptides have attracted attention as promising cancer therapeutics (46). The results of the present study in conjunction with those of previous observations highlight the NBD peptide as a peptide drug that can simultaneously inhibit tumor angiogenesis and cancer cell invasiveness. The NBD peptide is 60 amino acids in length. To improve the solubility, cell permeability and efficacy of the NBD peptide, identification of an essential core amino acid sequence capable of inhibiting the S100A4-MetAP2 interaction is undoubtedly required. Accordingly, the authors recently reported a peptide smaller than NBD, NBD- $\triangle \mathrm{N} 10$, a core peptide that can inhibit the S100A4-MetAP2 interaction (47). Further studies, including investigations of the effects of NBD- $\Delta$ N10 on tumor angiogenesis, invasion and metastasis, are warranted to develop an S100A4-based peptide drug that can efficiently inhibit tumor angiogenesis and tumor growth.

\section{Acknowledgements}

The authors would like to thank Professor J. Inoue of the Institute of Medical Science, the University of Tokyo, for providing helpful discussions.

\section{Funding}

The present study was supported in part by the Japan Arteriosclerosis Research Foundation. The funding bodies had 
no role in the design of the study, or data collection, analysis, or interpretation, or in the preparation of the manuscript.

\section{Availability of data and materials}

All data generated or analyzed are included in this published article (and in the included supplementary files).

\section{Authors' contributions}

HE conceived the experiments. KT and TO designed and performed the experiments and analyzed the data. KT wrote the manuscript. All authors read and approved the final manuscript.

\section{Ethics approval and consent to participate}

Animal experiments were performed in compliance with the guidelines of the Institute for Laboratory Animal Research, National Cancer Center Research Institute (February to March, 2019). The protocol was approved by the National Cancer Center Research Institute (Approval no. NCC-T17-038).

\section{Patient consent for publication}

Not applicable.

\section{Competing interests}

The authors declare that they have no competing interests.

\section{References}

1. Bjornland K, Winberg JO, Odegaard OT, Hovig E, Loennechen T, Aasen AO, Fodstad O and Maelandsmo GM: S100A4 involvement in metastasis: Deregulation of matrix metalloproteinases and tissue inhibitors of matrix metalloproteinases in osteosarcoma cells transfected with an anti-S100A4 ribozyme. Cancer Res 59: 4702-4708, 1999.

2. Buetti-Dinh A, Pivkin IV and Friedman R: S100A4 and its role in metastasis-simulations of knockout and amplification of epithelial growth factor receptor and matrix metalloproteinases. Mol Biosyst 11: 2247-2254, 2015.

3. Boye K and Maelandsmo GM: S100A4 and metastasis: A small actor playing many roles. Am J Pathol 176: 528-535, 2010.

4. Endo H, Takenaga K, Kanno T, Satoh H and Mori S: Methionine aminopeptidase 2 is a new target for the metastasis-associated protein, S100A4. J Biol Chem 277: 26396-26402, 2002.

5. Ochiya T, Takenaga K, Asagiri M, Nakano K, Satoh H, Watanabe T, Imajoh-Ohmi S and Endo H: Efficient inhibition of tumor angiogenesis and growth by a synthetic peptide blocking S100A4-methionine aminopeptidase 2 interaction. Mol Ther Methods Clin Dev 2: 15008, 2015.

6. Ishikawa M, Osaki M, Yamagishi M, Onuma K, Ito H, Okada F and Endo H: Correlation of two distinct metastasis-associated proteins, MTA1 and S100A4, in angiogenesis for promoting tumor growth. Oncogene 38: 4715-4728, 2019.

7. Kriajevska MV, Cardenas MN, Grigorian MS, Ambartsumian NS, Georgiev GP and Lukanidin EM: Non-muscle myosin heavy chain as a possible target for protein encoded by metastasis-related mts-1 gene. J Biol Chem 269: 19679-19682, 1994.

8. Kriajevska M, Bronstein IB, Scott DJ, Tarabykina S, Fischer-Larsen M, Issinger $\mathrm{O}$ and Lukanidin E: Metastasisassociated protein Mts1 (S100A4) inhibits CK2-mediated phosphorylation and self-assembly of the heavy chain of nonmuscle myosin. Biochim Biophys Acta 1498: 252-263, 2000.

9. Watanabe Y, Usada N, Minami H, Morita T, Tsugane S, Ishikawa R, Kohama K, Tomida $\mathrm{Y}$ and Hidaka H: Calvasculin, as a factor affecting the microfilament assemblies in rat fibroblasts transfected by src gene. FEBS Lett 324: 51-55, 1993.
10. Takenaga K, Nakamura Y, Sakiyama S, Hasegawa Y, Sato K and Endo H: Binding of pEL98 protein, an S100-related calcium-binding protein, to nonmuscle tropomyosin. J Cell Biol 124: 757-768, 1994

11. Kriajevska M, Fischer-Larsen M, Moertz E, Vorm O, Tulchinsky E, Grigorian M, Ambartsumian N and Lukanidin E: Liprin beta 1, a member of the family of LAR transmembrane tyrosine phosphatase-interacting proteins, is a new target for the metastasis-associated protein S100A4 (Mts1). J Biol Chem 277: 5229-5235, 2002.

12. Chen M, Bresnick AR and O'Connor KL: Coupling S100A4 to rhotekin alters Rho signaling output in breast cancer cells. Oncogene 32: 3754-3764, 2013.

13. Grigorian M, Andresen S, Tulchinsky E, Kriajevska M, Carlberg C, Kruse C, Cohn M, Ambartsumian N, Christensen A, Selivanova $\mathrm{G}$ and Lukanidin E: Tumor suppressor p53 protein is a new target for the metastasis-associated Mts1/S100A4 protein: Functional consequences of their interaction. J Biol Chem 276: 22699-22708, 2001.

14. Semov A, Moreno MJ, Onichtchenko A, Abulrob A, Ball M, Ekiel I, Pietrzynski G, Stanimirovic D and Alakhov V: Metastasis-associated protein S100A4 induces angiogenesis through interaction with Annexin II and accelerated plasmin formation. J Biol Chem 280: 20833-20841, 2005.

15. Okada H, Danoff TM, Kalluri R and Neilson EG: Early role of Fsp1 in epithelial-mesenchymal transformation. Am J Physiol 273: F563-F754, 1997.

16. Ning Q, Li F, Wang L, Li H, Yao Y, Hu T and Sun Z: S100A4 amplifies TGF- $\beta$-induced epithelial-mesenchymal transition in a pleural mesothelial cell line. J Investig Med 66: 334-339, 2018.

17. Chow KH, Park HJ, George J, Yamamoto K, Gallup AD, Graber JH, Chen Y, Jiang W, Steindler DA, Neilson EG, et al: S100A4 is a biomarker and regulator of glioma stem cells that is critical for mesenchymal transition in glioblastoma. Cancer Res 77: 5360-5373, 2017.

18. Lo JF, Yu CC, Chiou SH, Huang CY, Jan CI, Lin SC, Liu CJ, $\mathrm{Hu}$ EY and $\mathrm{Yu} \mathrm{YH}$ : The epithelial-mesenchymal transition mediator S100A4 maintains cancer-initiating cells in head and neck cancers. Cancer Res 71: 1912-1923, 2011.

19. Guo J, Bian Y, Wang Y, Chen L, Yu A and Sun X: S100A4 influences cancer stem cell-like properties of MGC803 gastric cancer cells by regulating GDF15 expression. Int J Oncol 49: 559-568, 2016.

20. Zhu Y, Zhou Y, Zhou X, Guo Y, Huang D, Zhang J, Wang C and Cai L: S100A4 suppresses cancer stem cell proliferation via interaction with the IKK/NF- $\mathrm{B}$ signaling pathway. BMC Cancer 18: 763, 2018.

21. Conlon GA and Murray GI: Recent advances in understanding the roles of matrix metalloproteinases in tumour invasion and metastasis. J Pathol 247: 629-640, 2018.

22. Cui N, Hu M and Khalil RA: Biochemical and biological attributes of matrix metalloproteinases. Prog Mol Biol Transl Sci 147: 1-73, 2017.

23. Castro-Castro A, Marchesin V, Monteiro P, Lodillinsky C, Rosse C and Chavrier P: Cellular and molecular mechanisms of MT1-MMP-dependent cancer cell invasion. Annu Rev Cell Dev Biol 32: 555-576, 2016.

24. Zarrabi K, Dufour A, Li J, Kuscu C, Pulkoski-Gross A, Zhi J, Hu Y, Sampson NS, Zucker S and Cao J: Inhibition of matrix metalloproteinase 14 (MMP-14)-mediated cancer cell migration. J Biol Chem 286: 33167-33177, 2011.

25. Kayano K, Shimada T, Shinomiya T, Nakai S, Hisa Y, Aoki T, Seiki $M$ and Okada Y: Activation of pro-MMP-2 mediated by MT1-MMP in human salivary gland carcinomas: Possible regulation of pro-MMP-2 activation by TIMP-2. J Pathol 202: 403-411, 2004.

26. Meirson $\mathrm{T}$ and Gil-Henn $\mathrm{H}$ : Targeting invadopodia for blocking breast cancer metastasis. Drug Resist Updat 39: 1-17, 2018.

27. Koshikawa N, Hoshino D, Taniguchi H, Minegishi T, Tomari T, Nam SO, Aoki M, Sueta T, Nakagawa T, Miyamoto S, et al: Proteolysis of EphA2 converts it from a tumor suppressor to an oncoprotein. Cancer Res 75: 3327-3339, 2015.

28. Sakamoto T and Seiki M: Integrated functions of membrane-type 1 matrix metalloproteinase in regulating cancer malignancy: Beyond a proteinase. Cancer Sci 108: 1095-1100, 2017.

29. Nishida-Aoki N, Tominaga N, Kosaka N and Ochiya T: Altered biodistribution of deglycosylated extracellular vesicles through enhanced cellular uptake. J Extracell Vesicles 9: 1713527, 2020.

30. Livak KJ and Schmittgen TD: Analysis of relative gene expression data using real-time quantitative PCR and the 2(-Delta Delta C(T)) method. Methods 25: 402-408, 2001. 
31. Schneider CA, Rasband WS and Eliceiri KW: NIH image to ImageJ: 25 years of image analysis. Nature Methods 9: 671-675, 2012.

32. Hirai M, Minematsu H, Kondo N, Oie K, Igarashi K and Yamazaki N: Accumulation of liposome with Sialyl Lewis $\mathrm{X}$ to inflammation and tumor region: Application to in vivo bio-imaging. Biochem Biophys Res Commun 353: 553-558, 2007.

33. Condeelis JS, Wyckoff JB, Bailly M, Pestell R, Lawrence D, Backer J and Segall JE: Lamellipodia in invasion. Semin Cancer Biol 11: 119-128, 2001.

34. Sroka IC, Nagle RB and Bowden GT: Membrane-type 1 matrix metalloproteinase is regulated by sp1 through the differential activation of AKT, JNK, and ERK pathways in human prostate tumor cells. Neoplasia 9: 406-417, 2007.

35. Hong IK, Byun HJ, Lee J, Jin YJ, Wang SJ, Jeoung DI, Kim YM and Lee H: The tetraspanin CD81 protein increases melanoma cell motility by up-regulating metalloproteinase MT1-MMP expression through the pro-oncogenic Akt-dependent Sp1 activation signaling pathways. J Biol Chem 289: 15691-15704, 2014.

36. Takino T, Nakada M,Li Z, Yoshimoto T, Domoto T and Sato H: Tip60 regulates MT1-MMP transcription and invasion of glioblastoma cells through NF-кB pathway. Clin Exp Metastasis 33: 45-52, 2016

37. Haas TL, Stitelman D, Davis SJ, Apte SS and Madri JA: Egr-1 mediates extracellular matrix-driven transcription of membrane type 1 matrix metalloproteinase in endothelium. J Biol Chem 274 22679-22685, 1999.

38. Heo SH, Lee JY, Yang KM and Park KS: ELK3 Expression correlates with cell migration, invasion, and membrane type 1-matrix metalloproteinase expression in MDA-MB-231 breast cancer cells. Gene Expr 16: 197-203, 2015.

39. Dulyaninova NG, Malashkevich VN, Almo SC and Bresnick AR: Regulation of myosin-IIA assembly and Mts1 binding by heavy chain phosphorylation. Biochemistry 44: 6867-6876, 2005.

40. Masedunskas A, Appaduray MA, Lucas CA, Cagigas ML, Heydecker M, Holliday M, Meiring JCM, Hook J, Kee A, White M, et al: Parallel assembly of actin and tropomyosin, but not myosin II, during de novo actin filament formation in live mice. J Cell Sci 131: jcs212654, 2018.
41. Lehtimaki J, Hakala M and Lappalainen P: Actin filament structures in migrating cells. Handb Exp Pharmacol 235: 123-152, 2017.

42. Tatematsu N, Waguri-Nagaya Y, Kawaguchi Y, Oguri Y, Ikuta K, Kobayashi M, Nozaki M, Asai K, Aoyama M and Otsuka T: Mithramycin has inhibitory effects on gliostatin and matrix metalloproteinase expression induced by gliostatin in rheumatoid fibroblast-like synoviocytes. Mod Rheumatol 28: 495-505, 2018.

43. Lee M, Song SU, Ryu JK and Suh JK: Sp1-dependent regulation of the tissue inhibitor of metalloproteinases-1 promoter. J Cell Biochem 91: 1260-1268, 2004

44. De Clerck YA, Darville MI, Eeckhout Y and Rousseau GG: Characterization of the promoter of the gene encoding human tissue inhibitor of metalloproteinases-2 (TIMP-2). Gene 139: 185-191, 1994.

45. Li DQ, Pakala SB, Reddy SDN, Ohshiro K, Zhang JX, Wang L, Zhang Y, de Alborán IM, Pillai MR, Eswaran J and Kumar R: Bidirectional autoregulatory mechanism of metastasis-associated protein 1-alternative reading frame pathway in oncogenesis. Proc Natl Acad Sci USA 108: 8791-8796, 2011.

46. Lau JL and Dunn MK: Therapeutic peptides: Historical perspectives, current development trends, and future directions. Bioorg Med Chem 26: 2700-2707, 2018.

47. Katagiri N, Nagatoishi S, Tsumoto K and Endo H: Structural features of methionine aminopeptidase2-active core peptide essential for binding with S100A4. Biochem Biophys Res Commun 516: 1123-1129, 2019.

(i) $\Theta$ This work is licensed under a Creative Common Attribution-NonCommercial-NoDerivatives 4.0 International (CC BY-NC-ND 4.0) License. 